\title{
Facile Synthesis of Magnetic Nitrogen-Doped Porous Carbon from Bimetallic Metal-Organic Frameworks for Efficient Norfloxacin Removal
}

\author{
Hui Wang ${ }^{1}$, Xi Zhang ${ }^{2}$, Yan Wang ${ }^{1}$, Guixiang Quan ${ }^{1}$, Xiangyun Han ${ }^{1}$ and Jinlong Yan ${ }^{1, *}$ \\ 1 School of Environmental Science and Engineering, Yancheng Institute of Technology, Yancheng 224051, China; \\ whsl@ycit.cn (H.W.); shanliangbang@163.com (Y.W.); qgx@ycit.cn (G.Q.); hxy16_2000@163.com (X.H.) \\ 2 College of Life and Environmental Science, Shanghai Normal University, Shanghai 200234, China; \\ m18321255826_1@163.com \\ * Correspondence: yjlyt@ycit.cn; Tel.: +86-515-8829-8805
}

Received: 6 August 2018; Accepted: 23 August 2018; Published: 26 August 2018

\begin{abstract}
Magnetic nitrogen-doped porous carbon (MNPC) has been prepared via self-catalytic pyrolysis of bimetallic metal-organic frameworks (MOFs). The as-obtained MNPC showed favorable features for antibiotics adsorption such as high specific surface area $\left(871 \mathrm{~m}^{2} \mathrm{~g}^{-1}\right)$, high pore volume $\left(0.75 \mathrm{~cm}^{3} \mathrm{~g}^{-1}\right)$, porous structure, good graphitization degree, and rich N-doping. Moreover, the MNPC has magnetic properties due to the Co species, which is embedded with a high dispersion, so the absorbent can be easily separated. Based on the above excellent characteristics, the MNPC was used as the absorbent for norfloxacin (NOR) removal. The experimental maximum NOR adsorption capacity of MNPC was $55.12 \mathrm{mg} \mathrm{g}^{-1}$ at $298.15 \mathrm{~K}$ and a $\mathrm{pH}$ of 6.0 with an initial NOR concentration of $50 \mathrm{mg} \mathrm{L}^{-1}$. The data analysis of the kinetics revealed that the experimental data of NOR uptakes versus time agreed with the pseudo-second order model. The isotherm data analysis revealed the favorable application of the Freundlich model. Based on the adsorption results over a wide range of conditions, the dominant adsorption mechanisms were found to be pore-filling, electrostatic interaction, and the $\mathrm{H}$-bond.
\end{abstract}

Keywords: self-catalytic pyrolysis; porous carbon; metal-organic frameworks; antibiotics; adsorption

\section{Introduction}

Over the past few decades, the emission of pharmaceutical compounds into the environment has sharply increased due to fast population growth and the rapid expansion of the pharmaceuticals industry. Antibiotics are one of most important type of pharmaceuticals, and are usually used as drugs or feed additives [1-4]. However, large amounts of antibiotics are stable and cannot be easily degraded, thus they are persistent in the environment. In addition, antibiotics could generate antibiotic-resistance genes in microorganisms, which can proliferate and widely disseminate in ecosystems. Fluoroquinolones are a commonly used antibiotic and their concentration is relatively high in the environment [5,6]. Norfloxacin (NOR) is one of the most frequently used fluoroquinolone antibiotics, and is always used to treat infectious diseases. It has been detected in the surface water and found to be toxic to aquatic organisms and human beings $[7,8]$. Therefore, it is necessary to develop a cost-effective method to remove NOR from wastewater.

Such methods as advanced oxidation, electrochemical methods, and biological treatments have been applied extensively to remove NOR from wastewaters. Among all of these methods, adsorption is the top priority owing to its simplicity, low operating cost, safety, and efficiency [9-11]. With such advantages as a large specific surface area and porous structure, carbon materials have been applied to remove NOR from water. For example, Xing et al. investigated the adsorption of norfloxacin (NOR) onto multiwall carbon nanotubes and activated carbon, and the results showed that activated carbon 
(AC) has a better NOR sorption capacity due to its higher surface area [12]. Theydan et al. prepared AC from a lignocellulosic biomass to remove NOR from water, and a maximum removal percentage of $98.13 \%$ was achieved [13]. Although a significant amount of research has been expended on adsorbing materials for antibiotics removal during the past few decades, development of novel adsorbents with higher performance is still needed.

As a new class of porous inorganic-organic materials, metal-organic frameworks (MOFs), have attracted wide attention owing to their high surface area and tunable pore size, which is widely used in areas of drug delivery, gas storage, and separation and catalysis [14-17]. Recently, MOFs have been used as templates or novel sources to prepare porous carbons through further carbonization. For example, $\mathrm{Xu}$ et al. applied MOFs as sacrificial templates to synthesis nanoporous carbons for the first time. They introduced furfuryl alcohol into the MOF-5 through a vapor phase protocol, which was then carbonized at $1000{ }^{\circ} \mathrm{C}$ under an inert atmosphere to obtain porous carbon [18]. Park et al. presented hierarchically porous carbon from highly crystalline MOFs and used it as a hydrogen storage adsorbent [19]. Most recently, Huang et al. demonstrated the application of MOF-derived porous carbon as an adsorbent for antibiotics removal. They prepared porous carbon through a one-step carbonization of zeolitic imidazolate framework-8 (ZIF-8), which showed a larger specific surface area due to the vaporization of the center metal ( $\mathrm{Zn}$ ) of ZIF-8 during the pyrolysis process. They were further used for ciprofloxacin removal from water [20]. Although porous carbon derived from ZIF-8 has a high specific surface area for antibiotics adsorption, it has limitations in terms of adsorption capacity and ease of separation.

Recently, the sustainability of the adsorption process has been advocated, such as: green adsorbent and green separation methods [21-23]. It has been demonstrated that the incorporation of magnetic nanoparticles on the surface of adsorbents can be engineered to allow the magnetic separation and recovery of the absorbents [24,25]. Wang et al. synthesized reduced graphene oxide/magnetite composites through an in situ reaction and utilized it as an adsorbent with a magnetically separable property for fluoroquinolone antibiotics [26]. Cai et al. encapsulated magnetic nanoparticles into carbon with a well-constructed core-shell structure, and then used it as an adsorbent for organic pollutants isolation [27]. However, the preparation of magnetic adsorbents usually needs additional processes to load the magnetic metal oxide, and it is difficult to control the dispersion of loaded particles during the synthesis process.

Herein, we report a simple but efficient solution process for the fabrication of a new form of magnetic nitrogen-doped porous carbon (MNPC) adsorbents for the NOR removal. The MNPC was directly synthesized by self-catalytic pyrolysis of bimetallic MOFs, which were prepared by using divalent $\mathrm{Zn}^{2+}$ and $\mathrm{Co}^{2+}$ as center metal ions and 2-methylimidazole as the ligand (Figure 1). In the carbonization process, the $\mathrm{Zn}$, with a boiling point of around $900{ }^{\circ} \mathrm{C}$, was evaporated during the calcination process, and the porous structure was formed simultaneously. Furthermore, the Co species were embedded in the porous structure with a high dispersion due to the coordination structure of the MOF's precursor, and so the MNPC had magnetic properties. Moreover, the Co species can act as catalyst to improve the graphitization degree of MNPC, which can enhance the adhesion between antibiotics and adsorbents through $\pi-\pi$ conjugation. More importantly, by the development of such multiple structures, the adsorption performance was significantly enhanced. 


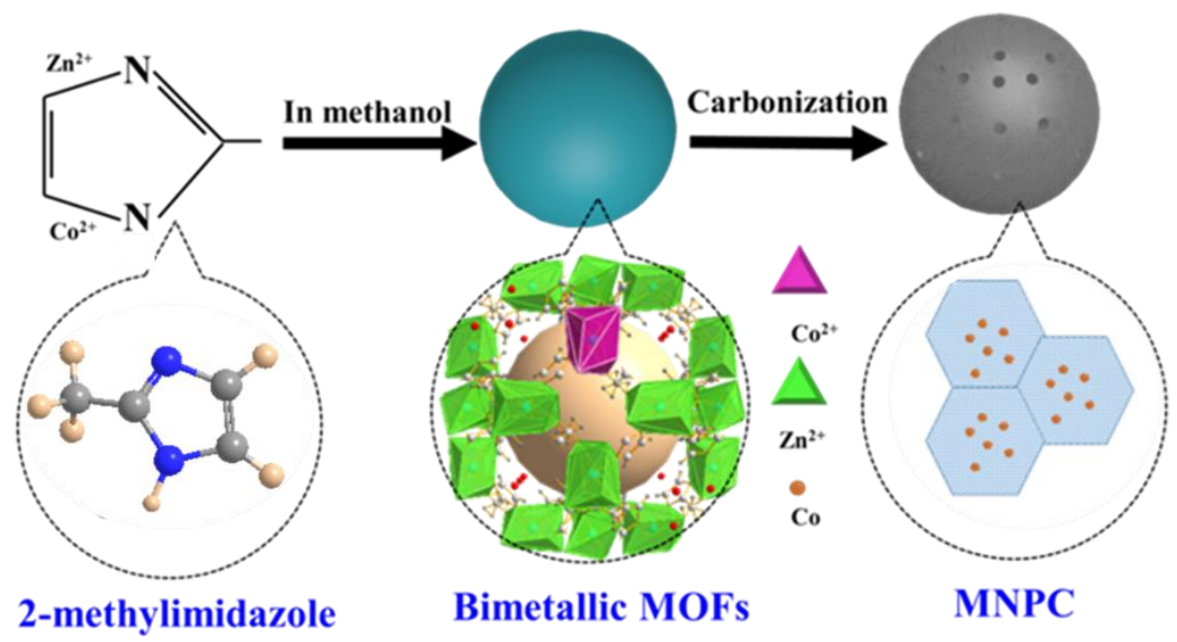

Figure 1. Schematic illustration of the construction process for the magnetic nitrogen-doped porous carbon (MNPC).

\section{Materials and Methods}

\subsection{Synthesis of $M N P C$}

Materials: The zinc nitrate hexahydrate $\left(\mathrm{Zn}\left(\mathrm{NO}_{3}\right)_{2} \cdot 6 \mathrm{H}_{2} \mathrm{O}\right)$, cobaltous nitrate hexahydrate $\left(\mathrm{Co}\left(\mathrm{NO}_{3}\right)_{2} \cdot 6 \mathrm{H}_{2} \mathrm{O}\right)$, 2-methylimidazole and norfloxacin were analytic grade provided by Aladdin Chemical Reagent Co., Ltd., Shanghai, China.

Synthesis of MNPC: Typically, $\mathrm{Co}\left(\mathrm{NO}_{3}\right)_{2} \cdot 6 \mathrm{H}_{2} \mathrm{O}(0.27 \mathrm{~g}, 0.9 \mathrm{mmol})$ and $\left(\mathrm{Zn}\left(\mathrm{NO}_{3}\right)_{2} \cdot 6 \mathrm{H}_{2} \mathrm{O}\right)(1.40 \mathrm{~g}$, $4.7 \mathrm{mmol}$ ) were first dissolved in $100 \mathrm{~mL}$ of methanol. 2-Methylimidazole $(3.70 \mathrm{~g}, 45.1 \mathrm{mmol}) \mathrm{in}$ $100 \mathrm{~mL}$ methanol was then added to the above solution. After quickly stirring for $24 \mathrm{~h}$, the products were separated by centrifugation and washed thoroughly with methanol. The obtained bimetallic MOFs were dried at $50{ }^{\circ} \mathrm{C}$ overnight, and further activated at $20{ }^{\circ} \mathrm{C}$ for $24 \mathrm{~h}$ under a vacuum before use. The as-synthesized bimetallic MOFs nanocrystals were heated to $950{ }^{\circ} \mathrm{C}$ with the ramp rate of $3{ }^{\circ} \mathrm{C} / \mathrm{min}$ under a $\mathrm{N}_{2}$ atmosphere and carbonized at $950{ }^{\circ} \mathrm{C}$ for $2 \mathrm{~h}$, and then cooled to room temperature naturally. Finally, the MNPC was entirely fabricated. The magnetic carbon (MC) prepared by MOFs with only Co ions as a central ion was used for comparison. The porous carbon (PC) prepared by MOFs with only $\mathrm{Zn}$ ions as a central ion was also prepared. In fact, the methanol used in this process could be recycled through membranes to realize sustainable fabrication $[28,29]$.

\subsection{Adsorption Performance of MNPC}

The adsorption experiments on NOR were conducted in $250 \mathrm{~mL}$ stopper conical flasks, and then placed in a thermostatic shaker with a speed of $200 \mathrm{rpm}$. In the adsorption experiment, $80 \mathrm{mg}$ of adsorbent was added to $100 \mathrm{~mL}$ of adsorbate solution. The influence of initial concentrations (5-50 mg L $\left.{ }^{-1}\right), \mathrm{pH}(2-10)$, temperature and ionic strength on the adsorption of NOR were also investigated. The solution $\mathrm{pH}$ was adjusted by dilute $\mathrm{HCl}$ or $\mathrm{NaOH}$ solution. The concentration of NOR was measured with a UV-Visible spectrophotometer (TU-1810, Beijing Purkinje General Instrument Co. Ltd., Beijing, China) at $272 \mathrm{~nm}$. The adsorbed capacity $(q)$ and removal rate $(\eta)$ were calculated according to the following equations:

$$
\begin{aligned}
& q=\left(C_{0}-C_{t}\right) V / m \\
& \eta=\left(C_{0}-C_{t}\right) / C_{0}
\end{aligned}
$$

where $C_{0}$ and $C_{t}\left(\mathrm{mg} \mathrm{L}^{-1}\right)$ represent the initial and final concentrations of NOR in the feed solution, respectively, $V$ is the volume of NOR solution (L), and $m$ is the dry mass of MNPC (g). 


\section{Results}

\subsection{Characterization}

The X-ray diffraction (XRD, Rigaku D/Max-RB, Rigaku Corporation, Tokyo, Japan) measurements is usually conducted to evaluate the structure of materials, and the XRD pattern of the MNPC is presented in Figure 2a. The MNPC shows an obvious diffraction peak at the $2 \theta=26^{\circ}$, corresponding to the (002) plane of the graphitic carbon [30]. The diffraction peaks located at around $44^{\circ}$ and $51^{\circ}$ are ascribed to $f c c$ Co, which is embedded in the carbon shell [31,32]. There was no characteristic peak of Zn in the XRD patterns due to the effective evaporation during the high-temperature calcination. The XRD pattern of MC was similar to that of MNPC (Figure S1). The graphitization degree of MNPC was further detected using Raman spectra (JY H800UV, Jobin-Yvon Corporation, Longjumeau, France), and the result is shown in Figure 2b. Two broad peaks at 1330 and $1583 \mathrm{~cm}^{-1}$ are obvious, and are related to the D-band and G-band, respectively. The D-band is associated with defects in the carbon structure, while the G-band is attributed to the vibration of $\mathrm{sp}^{2}$ carbon atoms in both the rings and chain [25]. The graphitization degree of MNPC can be found by calculating the ratios of the integrated intensities of the graphitic G-band to that of the disorder-induced D-band. As calculated, the value of $I_{\mathrm{G}} / I_{\mathrm{D}}$ was 1.07 , which was close to the MC (1.02, Figure S2a). However, the values of $I_{\mathrm{G}} / I_{\mathrm{D}}$ were higher than that of PC (0.94, Figure S2b) due to the catalytic action of Co.
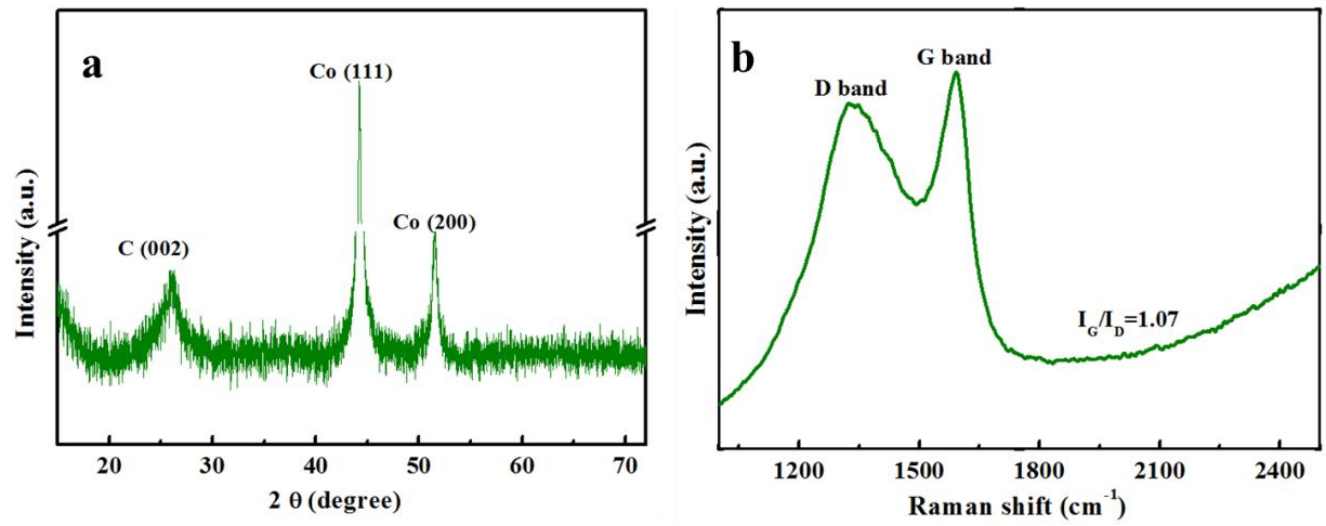

Figure 2. (a) X-ray diffraction (XRD) pattern and (b) Raman spectrum of the MNPC.

To further probe for the chemical identification of elements in the MNPC, the X-ray photoelectron spectroscopy (XPS, PHI-5000C ESCA system, Perkin-Elmer, Hopkinton, MA, USA) measurements were performed. According to the results, the elemental content of C, N, O, and Co was 80.29, 10.58, $7.19,1.95$ at \%, respectively. The C, N, O, and Co contents of MC are 90.67, 3.6, 4.38, and 1.34 at \%, respectively (Figure S3). The high-resolution C1s spectra (Figure 3a) could be fitted with three peaks at 284.6, 286.4, and $287.8 \mathrm{eV}$, corresponding to the $\mathrm{sp}^{2}$ aromatic rings, $\mathrm{C}-\mathrm{O}$, and $\mathrm{C}=\mathrm{O}$, respectively [33]. The peak of $\mathrm{sp}^{2}$ carbon showed the strongest intensity, indicating that the MNPC predominantly consisted of $\mathrm{sp}^{2}$-hybridized carbon due to the effective catalytic graphitization. As seen from the high-resolution N1s (Figure 3b), three different types of nitrogen species were well deconvoluted. The N-6 atoms were located at $398.5 \mathrm{eV}$, and were bonded with two carbon atoms in a $\mathrm{C}_{6}$ ring, so a pair of lone electrons could be introduced simultaneously. This was beneficial to the formation of a hydrogen bond with the NOR molecule. The N-5 was centered at $400.4 \mathrm{eV}$, associated with the adjacent phenolic or carbonyl group. The N-Q atoms bond with three carbon atoms in the center of graphitic plane [34,35]. The additional N-doping can increase the adsorption sites for NOR, and further improve the adsorption performance of MNPC. 

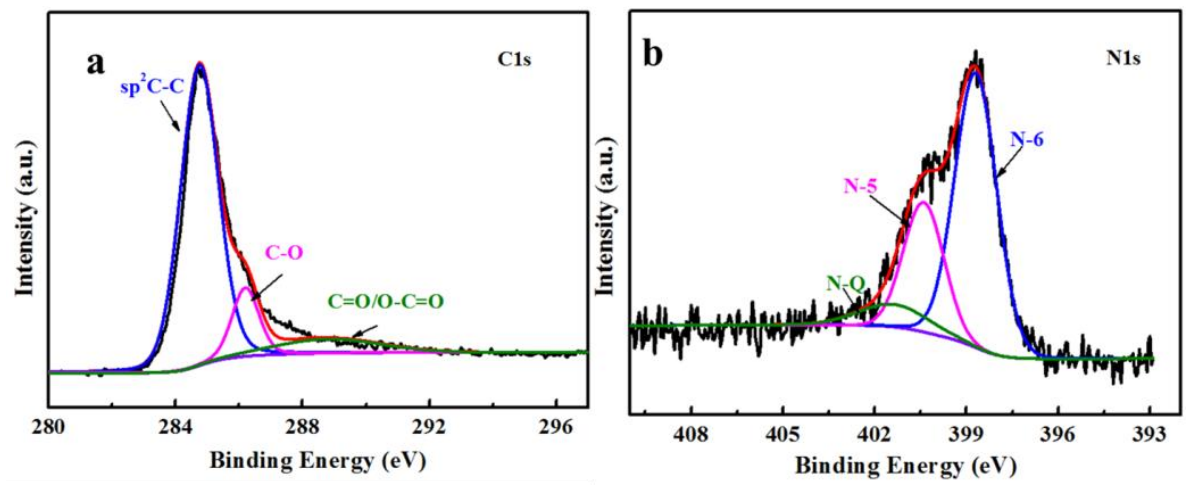

Figure 3. (a) $\mathrm{C} 1 \mathrm{~s}$ spectra and (b) $\mathrm{N}$ 1s spectra of the MNPC.

The $\mathrm{N}_{2}$ sorption isothermal (ASAP 2020, Micromeritics Inc., Norcross, GA, USA) was further examined to analyze the pore structure of MNPC. As seen from Figure $4 \mathrm{a}$, the MNPC showed a typical IV-type isotherm with a hysteresis loop at $p / p_{0}=0.4-1.0$ (inset), indicating the mesoporous structure of MNPC [36]. Figure $4 \mathrm{~b}$ shows the Barrett-Joyner-Halenda (BJH) pore size distribution profile of MNPC derived from desorption branches of isotherms. Clearly, the MNPC pores' radii was mainly concentrated at $2.0 \mathrm{~nm}$, further indicating that the mesopores were dominant in the structure of MNPC. The specific surface area of MNPC was $871 \mathrm{~m}^{2} \mathrm{~g}^{-1}$, much larger than that of MC obtained with the absence of a $\mathrm{Zn}$ ion (Figure S4). With $\mathrm{Zn}$ coordination, the $\mathrm{ZnO}$ would be formed during the carbonization process, which can act as sacrificial template accelerating the formation of the porous structure of MNPC $[37,38]$. Furthermore, the pore volume of MNPC was $0.76 \mathrm{~cm}^{3} \mathrm{~g}^{-1}$ (Figure $4 \mathrm{~b}$ ), which is much larger than that of MC $\left(0.16 \mathrm{~cm}^{3} \mathrm{~g}^{-1}\right)$. The increased specific surface area and pore volume are favorable for increasing the accessible surface area for NOR accumulation during the adsorption process and then enhance the adsorption capacity.
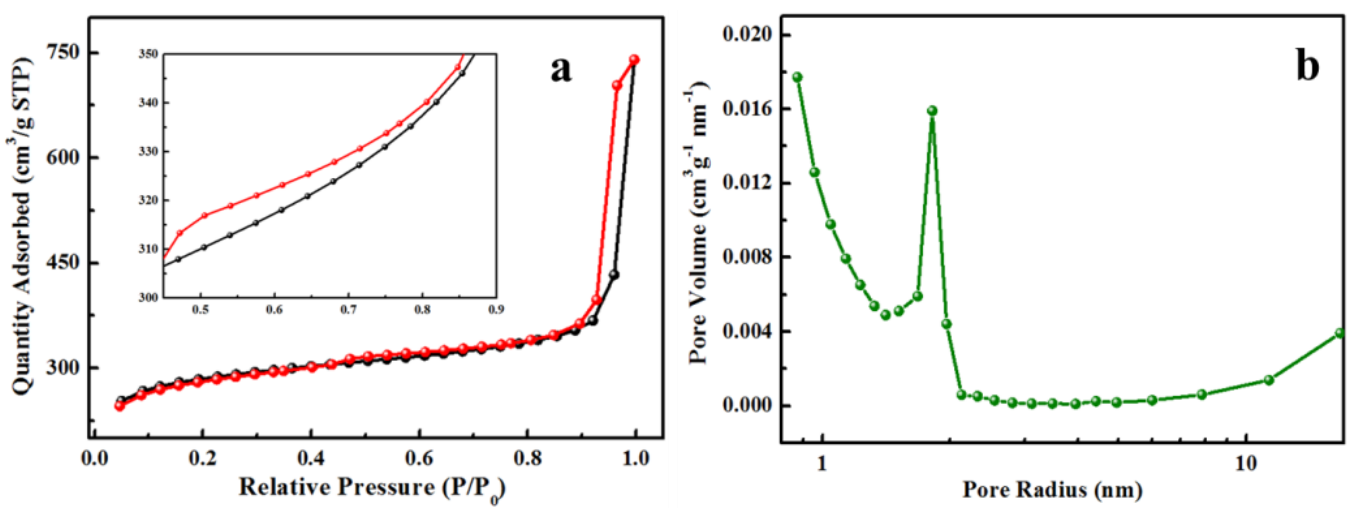

Figure 4. (a) $\mathrm{N}_{2}$ sorption isotherm and (b) pore size distribution of the MNPC.

The surface morphology of MNPC was investigated with scanning electron microscopy (SEM, JEOL JSM-6700F, Tokyo, Japan) and transmission electron microscopy (TEM, JEOL JEM-200CX, Tokyo, Japan). As seen from the SEM image in Figure $5 a$, the bimetallic MOFs precursor shows a cubic-like structure with an average size of $50 \mathrm{~nm}$. After pyrolysis at $950{ }^{\circ} \mathrm{C}$, the $\mathrm{Zn}$ species were volatilized, and the pores left simultaneously [38]. Moreover, the MNPC retained the morphology of the MOF's precursor with a good dispersion (Figure $5 b$ ). This indicates that the structure kept well, even after the high-temperature calcination. The TEM image in Figure $5 c$ reveals that the MNPC had a uniform morphology with an interconnected porous structure, and the Co nanopaticals (NPs) were embedded in the porous carbon. The high-resolution transmission electron microscopy (HRTEM) image (Figure 5d) shows further that MNPC exhibits an obvious core-shell structure. The graphitic carbon structures 
were the shells with an interplane spacing of (002) crystal lattice (3.4 $\AA$ ), which resulted from the catalytic graphitization behavior of Co NPs [31]. Moreover, the Co NPs were tightly wrapped by graphitic carbon shells due to the coordinating structures of bimetallic MOFs as a precursor. In addition, the HRTEM image shows a distinct lattice fringe with an interplanar spacing of $0.2 \mathrm{~nm}$, which matched well with the spacing of (111) planes of the Co phase. Besides, the MC showed a dodecahedron-like structure with a particle size around $250 \mathrm{~nm}$, and the Co also embedded in the carbon structure (Figure S5).

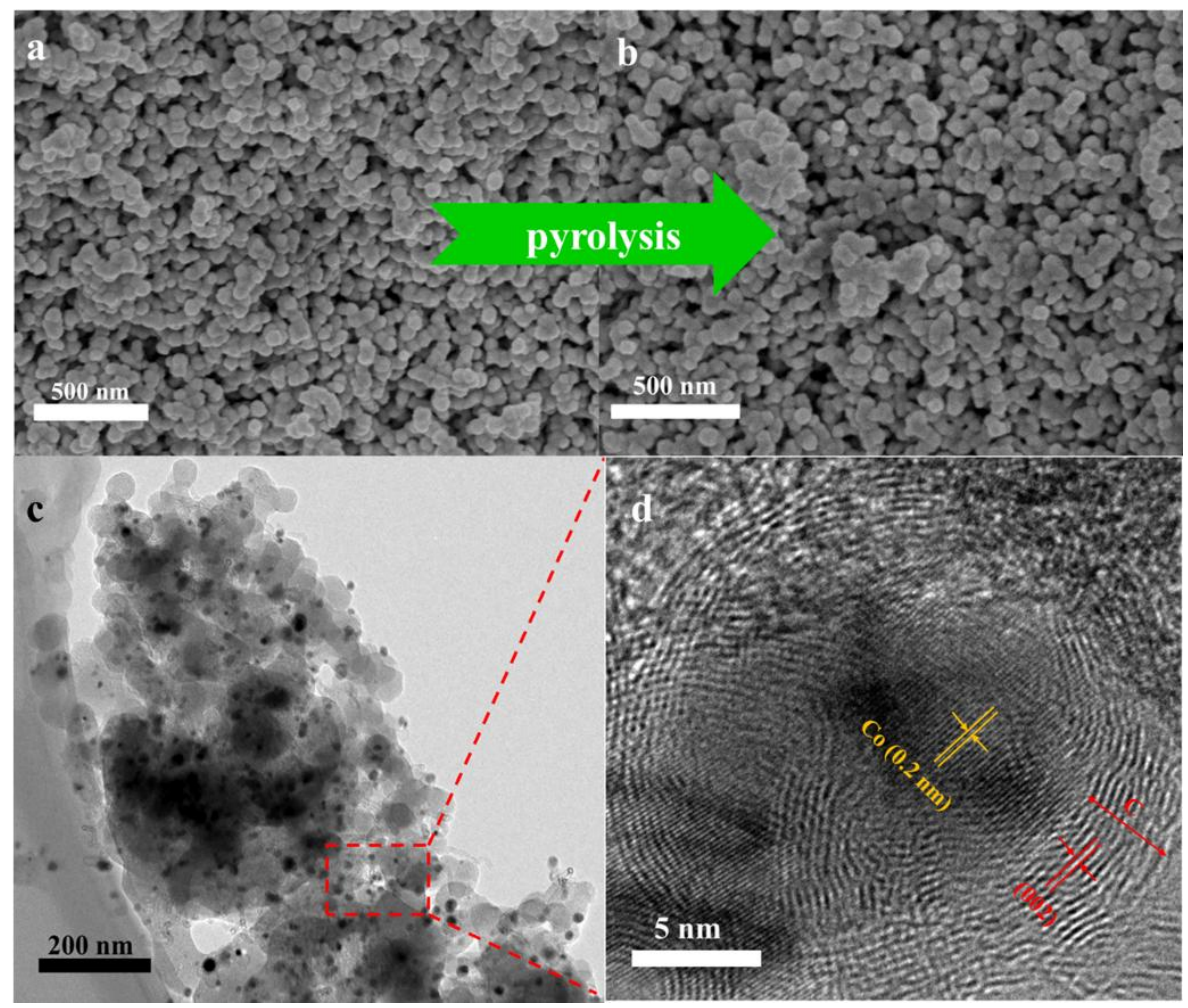

Figure 5. SEM images of (a) Bimetallic metal-organic frameworks (MOFs) precursor; and (b) the MNPC; (c) TEM and (d) HRTEM images of the MNPC.

As seen from the high-angle annular dark field-scanning electron microscopy (HAADF-STEM) (Figure 6a), The Co NPs were embedded into graphitic carbon structure. The elemental mapping was performed to illustrate the spatial distribution of $\mathrm{C}, \mathrm{N}, \mathrm{O}$, and Co in the structure of MNPC in Figure $6 \mathrm{~b}$. As revealed in Figure $6 \mathrm{c}-\mathrm{f}$, the elemental mapping results further confirmed the uniform distribution of $\mathrm{Co}$ and $\mathrm{N}$ species within the MNPC structure. Besides, the MC also showed a homogeneous distribution (Figure S5). It is generally accepted that the $\mathrm{N}$ species can promote the formation of hydrogen bonds and accelerate the adsorption performance. Moreover, the Co species with a good dispersion within the carbon structure is beneficial to the further separation of adsorbents. 


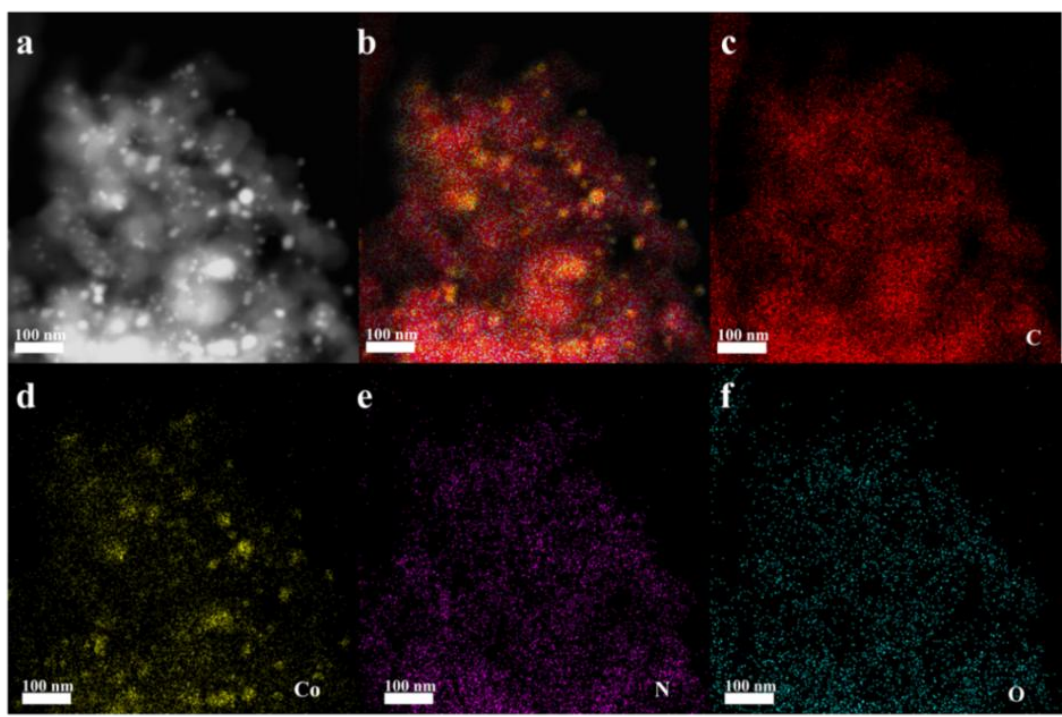

Figure 6. The high-angle annular dark field-scanning electron microscopy (HAADF-STEM): (a) image, and (b-f) mapping images of MNPC.

\subsection{Adsorption Performance}

The adsorption behavior of the MNPC on the NOR was investigated by batch mode experiments in $10 \mathrm{mg} \mathrm{L}^{-1}$ aqueous solution. As seen from the adsorption curves in Figure 7, the adsorption capacity sharply increased with the adsorption time, suggesting that the NOR in the aqueous solution could be quickly and easily removed by the adsorbents [39]. As time goes on, the change of adsorption capacity became slower until reaching an adsorption equilibrium owing to the fact that the number of adsorption sites decreased as the adsorption time increased. Obviously, the adsorption capacity of the MNPC adsorbents was much larger than that of MC, indicating that the MNPC exhibited much better adsorption performance. After $150 \mathrm{~min}$, the final adsorption capacity of MNPC adsorbents was $8.84 \mathrm{mg} \mathrm{g}^{-1}$, larger than that of MC $\left(7.98 \mathrm{mg} \mathrm{g}^{-1}\right)$. As seen from the Figure $7 \mathrm{~b}$, the MNPC in the aqueous solution could be easily separated under an external magnetic field.

The better adsorption performance of MNPC adsorbents can be ascribed to the following aspects: First, the larger specific surface area of MNPC can provide more adsorption sites for the NOR adsorption. Second, the NOR molecules can be easily transported between the smooth channels in the MNPC due to the interconnected porous structure. Moreover, the MNPC has a good graphitization degree, which is beneficial to the formation of $\pi-\pi$ interactions between NOR and absorbents, which then further improves the adsorption capacity $[8,40]$. Furthermore, hydrogen bonding is easy to form between MNPC adsorbents and NOR due to the effect of nitrogen doping, which further promotes adsorption performance [38]. In conclusion, combining the pore structure, large specific surface area, good graphitization degree, and the effective nitrogen doping, MNPC can be considered as an excellent candidate material for NOR adsorption application.

As is well known, the structure and surface properties of adsorbents have important influence on the adsorption performance. Generally, the adsorbent's structure has a great effect on the physical adsorption, and the chemical adsorption is usually related to the functional groups on the surface of adsorbents [41]. The MNPC has large specific surface area, which can provide abundant adsorption sites for NOR adsorption. The porous structure is beneficial to the NOR molecules' penetration. In addition, such oxygen-containing functional groups as $-\mathrm{COOH}$ and $-\mathrm{OH}$ and $\mathrm{N}$-doping are on the surface of MNPC, so the hydrogen bonding can be easily formed between the NOR molecules the MNPC, which then promotes the adsorption capacity [8]. Moreover, the aromatic structures and $\mathrm{C}=\mathrm{C}$ double bonds in NOR can contribute to the affinity between MNPC and NOR through the $\pi-\pi$ interactions and then increase the adsorption capacity [42]. 


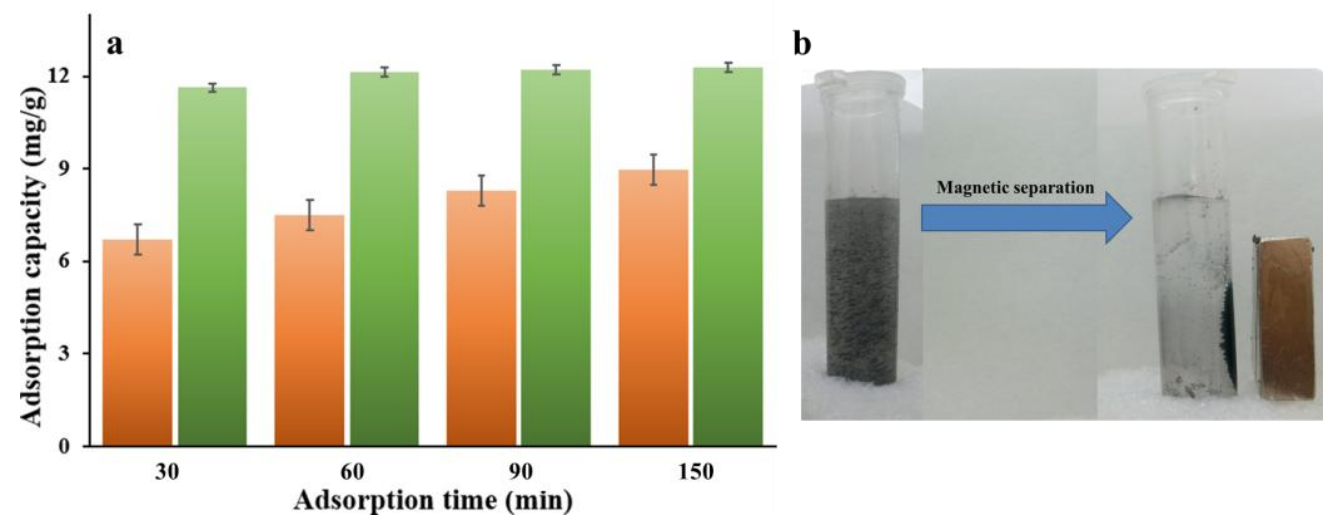

Figure 7. (a) Plots of adsorption capacity vs adsorption time of MNPC and MC in the NOR aqueous solutions at concentrations of $10 \mathrm{mg} \mathrm{L}^{-1}$; and (b) the photo of MNPC separated under an external magnetic field.

As is well known, the amount of adsorbents has a critical effect on the adsorption performance. The influence of the adsorbent's dosage was explored by adding various amounts of MNPC to $100 \mathrm{~mL}$ of a $10 \mathrm{mg} \mathrm{L}^{-1}$ NOR solution. As seen from Figure $8 \mathrm{a}$, the adsorption capacity decreased with the increase of the absorbent's dosage due to the completely exposed adsorption sites at the low dosage. While at higher dosage, the unoccupied adsorption sites were excess and resulted in a lower adsorption capacity [43]. Considering the adsorbent amounts and adsorption capacity, an $0.8 \mathrm{~g} / \mathrm{L}$ dosage of MNPC was selected for further studies.
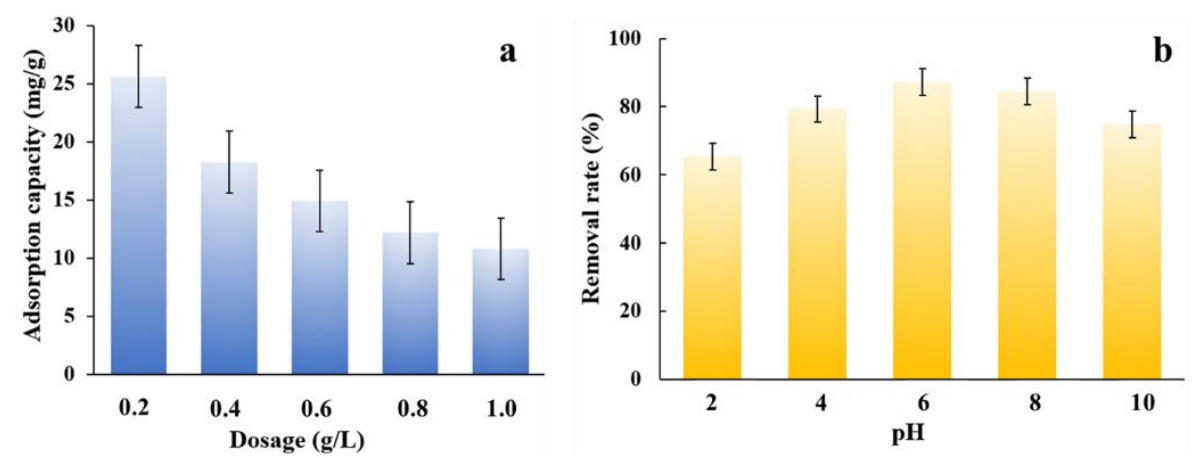

Figure 8. (a) Plots of adsorption capacity vs dosage; and (b) plots of removal rates vs. pH value with a dosage of $0.8 \mathrm{~g} \mathrm{~L}^{-1}$. All the curves were obtained in a $10 \mathrm{mg} \mathrm{L}^{-1} \mathrm{NOR}$ aqueous solution at $30^{\circ} \mathrm{C}$.

$\mathrm{pH}$ is another important factor affecting adsorption performance. As seen in Figure $8 \mathrm{~b}$, the NOR adsorption on MNPC initially increased with the $\mathrm{pH}$ value ranging from 2.0 to 6.0, and then decreased when the solution $\mathrm{pH}$ value was higher than 6.0. The NOR contained a carboxyl and piperazinyl group, which shows two proton-binding sites. Its two acid dissociation constant $\mathrm{pKa}$ values were 6.22 and 8.51, respectively. In the solution, the protonation-deprotonation reaction of NOR would occur. The NOR can exist in cationic form $(\mathrm{pH}<6.2)$, zwitterionic/neutral form $(6.2<\mathrm{pH}<8.5)$, or anionic form $(\mathrm{pH}>8.5)[8,12]$. In acidic conditions, a large amount of $\mathrm{H}^{+}$ions surrounds the surface of MNPC, which could compete with the NOR molecule existing in the cationic form, and so the binding of NOR to adsorbent is restricted. When the $\mathrm{pH}$ value ranges from 6.0 to 8.7 , the ratio of the zwitterion form is increased, so the competition between $\mathrm{H}^{+}$and NOR ions for surface adsorption sites is decreased correspondingly, resulting in an improved adsorption capacity. However, when the $\mathrm{pH}$ is higher than the $\mathrm{pKa}_{2}$ of $\mathrm{NOR}$, the anionic form dominates and the repulsion between the 
NOR molecule and the negatively charged MNPC is increased, and so the adsorption capacity is significantly decreased. The further studies were conducted at the optimum $\mathrm{pH}$ value of 6.0.

The initial NOR concentration is another key factor controlling the adsorption performance of MNPC, as shown in Figure 9a. The initial NOR concentration ranged from 1.0 to $100 \mathrm{mg} \mathrm{L}^{-1}$ at a pH of 6.0. Obviously, the adsorption capacity is increased with the solution concentration, which was increased from 3.04 to $55.12 \mathrm{mg} \mathrm{g}^{-1}$. A higher initial NOR concentration meant a higher concentration gradient, which led to a high driving force, and so the NOR molecules could quickly transfer to the pores of the MNPC. As shown in Figure 9b, the adsorption capacity of MNPC for NOR increased with increased temperature $\left(20-40^{\circ} \mathrm{C}\right)$, suggesting that the higher temperature was beneficial to the adsorption process.
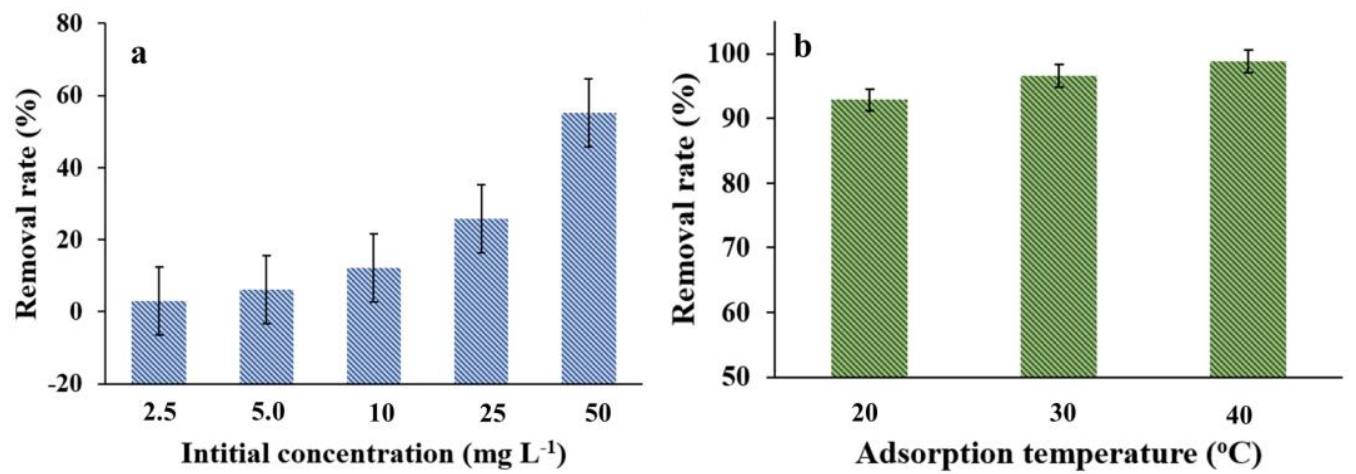

Figure 9. (a) The change of adsorption capacity vs initial concentration; and (b) the change of adsorption rates vs. temperature. All the curves were obtained in NOR solution with a dosage of $0.8 \mathrm{~g} \mathrm{~L}^{-1}$ at a pH of 7.0 .

The influence of ionic strength on the adsorption performance was also investigated and the results are shown in Figure 10. When the salt concentration increased from 0.0 to $0.1 \mathrm{M}$, the adsorption capacity decreased slightly. Generally, the salt concentration had no significant effect on the adsorption capacity of NOR on the MNPC, which indicates that the interaction between NOR and MNPC was quite stable in a certain range of salt concentration.

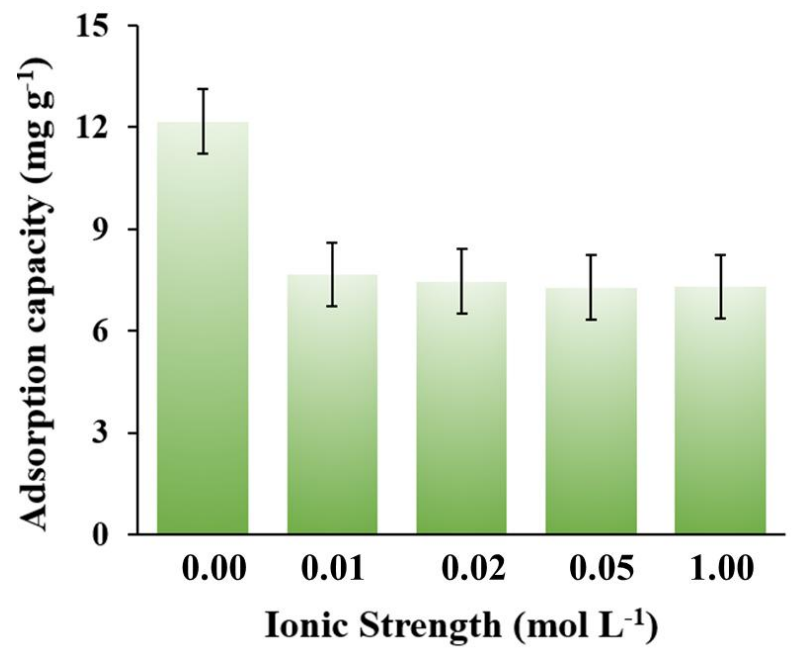

Figure 10. Plots of adsorption capacity vs ionic strength. All the curves were obtained in $10 \mathrm{mg} \mathrm{L}^{-1}$ NOR aqueous solution with a dosage of $0.8 \mathrm{~g} \mathrm{~L}^{-1}$ at a $\mathrm{pH}$ of 7.0. 


\subsection{Recyclability}

In practical application, the recyclability is another critical factor for the adsorbents. The recyclability of the MNPC was investigated using a methanol solution (containing 10\% ammonia) as the effluents and the results are shown in Figure 11. The adsorption capacity of the MNPC remained at $12.0 \mathrm{mg} \mathrm{g}^{-1}$ after five cycles, and was slightly decreased, indicating the good regeneration performance of the absorbents in the NOR solution. Hence, the MNPC adsorbent could be reused effectively, which is helpful for reducing the cost of adsorption.

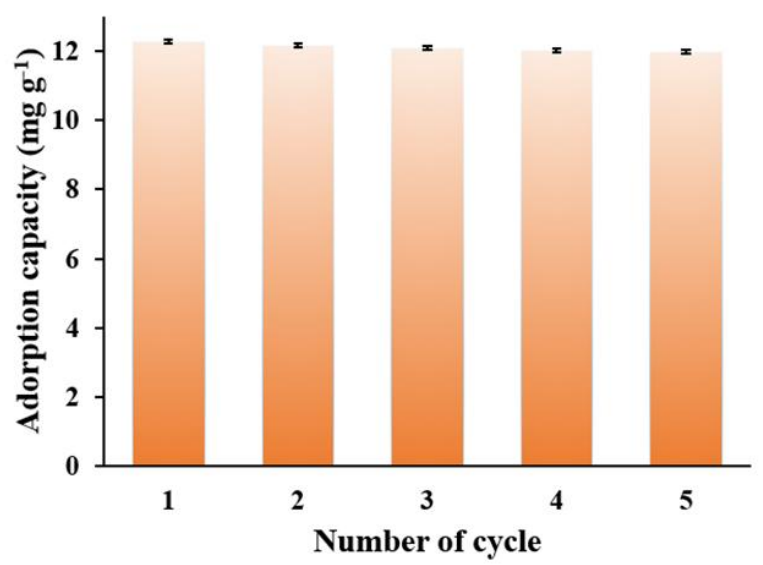

Figure 11. Regeneration property of the MNPC adsorbents in the $10 \mathrm{mg} \mathrm{L}^{-1}$ norfloxacin (NOR) aqueous solution with a dosage of $0.8 \mathrm{~g} \mathrm{~L}^{-1}$ at a $\mathrm{pH}$ of 7 .

\subsection{Adsorption Kinetics}

Adsorption kinetic models are usually used to evaluate the variation of adsorption capacity with adsorption time, which can further reflect the relationship between adsorption performance and the structure of adsorbent. In this work, the pseudo-first-order and pseudo-second-order models were employed to analyze the experimental data. These two models are shown as follows:

$$
\begin{gathered}
\ln \left(q_{\mathrm{e}}-q_{t}\right)=\ln q_{\mathrm{e}}-\mathrm{k}_{1} t \\
\frac{t}{q_{t}}=\frac{1}{\mathrm{k}_{2} q_{\mathrm{e}}^{2}}+\frac{t}{q_{\mathrm{e}}}
\end{gathered}
$$

where $q_{\mathrm{e}}$ and $q_{\mathrm{t}}\left(\mathrm{mg} \mathrm{g}^{-1}\right)$ are NOR uptakes at equilibrium, $t$ is the adsorption time, and $\mathrm{k}_{1}\left(\mathrm{~min}^{-1}\right)$ and $\mathrm{k}_{2}\left(\mathrm{~g} \mathrm{mg}^{-1} \mathrm{~min}^{-1}\right)$ are the rate constants of two modes [44,45].

Figure 12 shows the results of fitting the two kinetic models. As seen from the Figure 11a, the experimental data severely deviates from the fitted data, and the $R^{2}$ value of the pseudo-first order model was relatively low, indicating a low correlation of NOR adsorption kinetics data, and so the pseudo-first-order model was inconsistent with the experimental data. However, the experimental adsorption capacity values were in agreement with the theoretical adsorption capacity values according to the pseudo-second-order model (Figure $11 \mathrm{~b}$ ) with a corresponding $R^{2}$ of 0.9996 , illustrating that the adsorption data fit well to the pseudo-second-order kinetic model. 

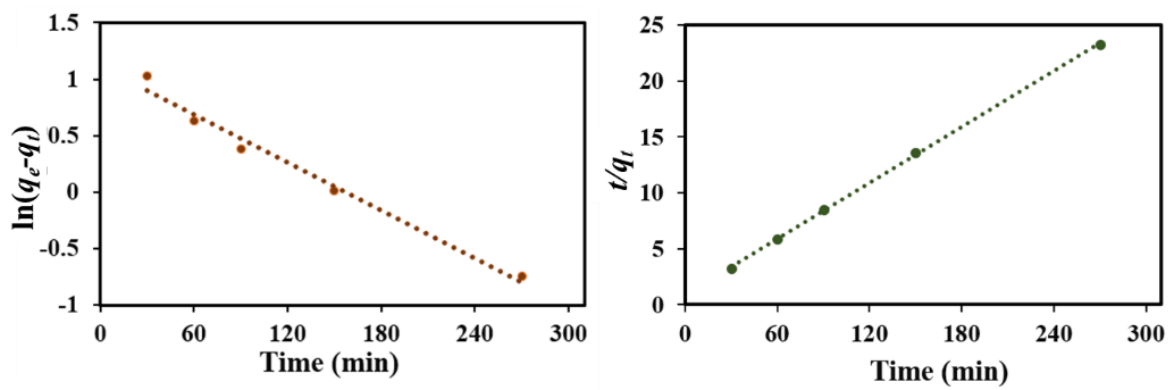

Figure 12. Adsorption kinetics of NOR on MNPC (a) pseudo-first-order and (b) pseudo-second-order models.

\subsection{Adsorption Isotherm}

To further study how the adsorbate interacts with the adsorbent, the adsorption models have been applied to understand the adsorption mechanism. Thus the Freundlich and Langmuir adsorption isotherm models were used according to:

$$
\begin{aligned}
q_{\mathrm{e}} & =\frac{q_{\mathrm{m}} K_{\mathrm{L}} C_{\mathrm{e}}}{1+K_{\mathrm{L}} C_{\mathrm{e}}} \\
q_{\mathrm{e}} & =K_{\mathrm{F}} C_{\mathrm{e}}^{1 / \mathrm{n}}
\end{aligned}
$$

where $q_{\mathrm{e}}, q_{\mathrm{m}}$, and $C_{\mathrm{e}}\left(\mathrm{mg} \mathrm{g}^{-1}\right)$ are the adsorption capacity, equilibrium concentration, and the maximum adsorption capacity, respectively, and $K_{\mathrm{L}}, K_{\mathrm{F}}$, and $n$ are the Langmuir and Freundlich parameters [13]. Figure 13 displays both the experimental data and the fitting isotherms of the above two isotherm models. According to the results, the adsorption isotherm of NOR onto the MNPC fits Freundlich isotherm model with higher correlation coefficients $R^{2}$ values (0.9988) compared with the Langmuir isotherm model (0.9841, Figure S6), indicating that the adsorption process predominantly features multilayer adsorption.

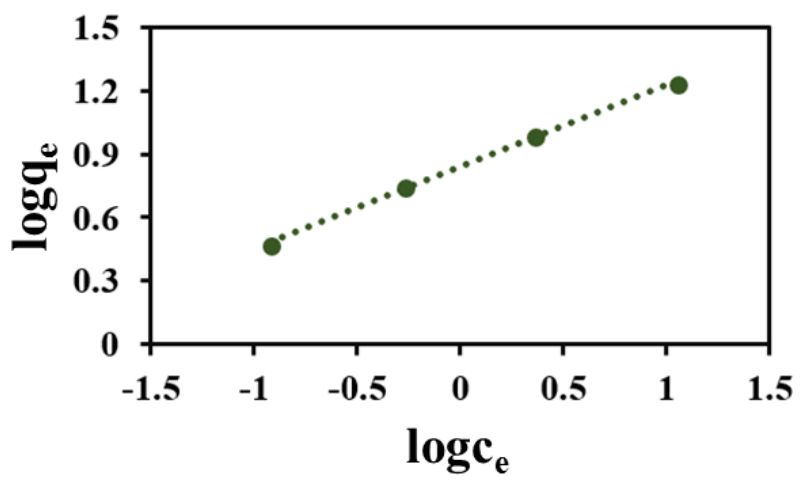

Figure 13. Freundlich isotherms for the adsorption of NOR by MNPC at $30^{\circ} \mathrm{C}$.

\subsection{Adsorption Thermodynamics}

The adsorption of NOR on the MNPC was further demonstrated by evaluation of changes in the Gibbs free energy $\left(\triangle G^{\theta}\right)$, enthalpy $\left(\triangle H^{\theta}\right)$, and entropy $\left(\triangle S^{\theta}\right)$ as follows:

$$
\begin{gathered}
\Delta G^{\theta}=-R T \ln K_{\mathrm{c}} \\
K_{\mathrm{c}}=\frac{C_{\mathrm{A}}}{C_{\mathrm{S}}}
\end{gathered}
$$


where $R$ is the ideal gas constant, $T$ represents absolute temperature $(K), C_{A}$ and $C_{S}\left(\mathrm{mg} \mathrm{L}^{-1}\right)$ are the amount of NOR adsorbed and remained in the solution at equilibrium, respectively. After making the substituting of $\triangle G^{\theta}=\triangle H^{\theta}-T \triangle S^{\theta}$ into Equation (9):

$$
\ln \left(K_{\mathrm{c}}\right)=-\frac{\Delta G^{\theta}}{\mathrm{RT}}=-\frac{\Delta H^{\theta}}{\mathrm{RT}}+\frac{\Delta S^{\theta}}{\mathrm{R}}
$$

The values of $\triangle H^{\theta}$ and $\triangle S^{\theta}$ were then calculated from the slope and intercept of the linear regression of $\ln \left(K_{\mathrm{c}}\right)$ versus $1 / \mathrm{T}$ [41]. As calculated, the value of $\triangle H^{\theta}$ was $70.08 \mathrm{~kJ} \cdot \mathrm{mol}^{-1}$, indicating that sorption of NOR on the MNPC was an exothermic process. Moreover, the value of $\triangle H^{\theta}$ was higher than $20 \mathrm{~kJ} \cdot \mathrm{mol}^{-1}$, indicating the NOR sorption onto MNPC could be mainly attributed to chemisorption. Another important thermodynamic parameter is entropy $\triangle G^{\theta}$. As calculated, the $\triangle G^{\theta}$ value was negative, indicating that the adsorption could occur spontaneously.

\section{Conclusions}

The MNPC was successfully prepared by self-catalytic pyrolysis of bimetallic MOF with Zn and $\mathrm{Co}$ as metal ions and 2-methylimidazole as a ligand. The resultant MNPC possessed a large surface area, porous structure, good graphitization, and highly dispersed N species, simultaneously. The synergistic effect of the above characteristics offered MNPC excellent adsorption performances. The MNPC exhibited a dramatic enhancement in the adsorption to NOR compared with the MC derived from the MOF with only $\mathrm{Co}$ as the metal ion. The adsorption capacity was $55.12 \mathrm{mg} \mathrm{g}^{-1}$ with an initial concentration of $50 \mathrm{mg} \mathrm{L}^{-1}$ at $30{ }^{\circ} \mathrm{C}$. The pseudo-second-order and Freundlich models were a good fit for adsorption kinetics and isotherm for NOR adsorption. In the process of NOR adsorption onto the MNPC, the $\pi-\pi$ interaction, hydrogen bonding, and pore-filling significantly improved the adsorption capability. Overall, this material is a potential adsorbent for the NOR and is expected to be used for removal of other pollutants in waste water.

Supplementary Materials: The following are available online at http:/ /www.mdpi.com/2079-4991/8/9/664/s1, Figure S1: XRD pattern of MC, Figure S2: Raman spectra of (a) MC and (b) PC, Figure S3: The XPS spectra of MC and MNPC, C1s and N1s of MC, Figure S4: $\mathrm{N}_{2}$ sorption isotherm of MC, Figure S5: (a) SEM, (b) TEM, (c) HRTEM and mapping images of MC, Figure S6: Langmuir isotherm of NOR adsorption on the MNPC at $30{ }^{\circ} \mathrm{C}$.

Author Contributions: Conceptualization, Hui, Wang and Jinlong, Yan; Methodology, Xi, Zhang and Yan, Wang; Validation, Xiangyun Han; Formal Analysis, Hui, Wang; Investigation, Xiangyun Han; Resources, Hui, Wang; Data Curation, Hui, Wang and Xiangyun Han; Writing-Original Draft Preparation, Hui, Wang.; Writing-Review \& Editing, Jinlong, Yan; Visualization, Guixiang Quan; Supervision, Jinlong Yan; Project Administration, Hui, Wang; Funding Acquisition, Hui Wang.

Funding: This research was funded by the Natural Science Foundation of Jiangsu Province-Youth Fund Project (BK20170475) and National Natural Science Foundation of China (21677119).

Acknowledgments: The authors would like to thank C. J. Ma from Analysis and Test Center of Yancheng Institute of Technology, for help with the TEM measurements.

Conflicts of Interest: The authors declare no conflict of interest

\section{References}

1. Zhang, H.; Jia, Y.; Khanal, S.K.; Lu, H.; Fang, H.; Zhao, Q. Understanding the role of extracellular polymeric substances (EPS) on ciprofloxacin (CIP) adsorption in aerobic sludge, anaerobic sludge and sulfate-reducing bacteria (SRB) sludge systems. Environ. Sci. Technol. 2018, 52, 6476-6486. [CrossRef] [PubMed]

2. Xiao, T.; Tang, Z.; Yang, Y.; Tang, L.; Zhou, Y.; Zou, Z. In situ construction of hierarchical $\mathrm{WO}_{3} / \mathrm{g}-\mathrm{C}_{3} \mathrm{~N}_{4}$ composite hollow microspheres as a Z-scheme photocatalyst for the degradation of antibiotics. Appl. Catal. B 2018, 220, 417-428. [CrossRef]

3. Wang, S.; Li, X.; Zhao, N.; Quan, X.; Chen, S.; Yu, H. Enhanced adsorption of ionizable antibiotics on activated carbon fiber under electrochemical assistance in continuous-flow modes. Water Res. 2018, 134, 162-169. [CrossRef] [PubMed] 
4. Wu, H.; Li, C.; Che, H.; Hu, H.; Hu, W.; Liu, C.; Ai, J.; Dong, H. Decoration of mesoporous $\mathrm{Co}_{3} \mathrm{O}_{4}$ nanospheres assembled by monocrystal nanodots on $\mathrm{g}-\mathrm{C}_{3} \mathrm{~N}_{4}$ to construct Z-scheme system for improving photocatalytic performance. Appl. Surf. Sci. 2018, 440, 308-319. [CrossRef]

5. Wang, B.; Lv, X.L.; Feng, D.; Xie, L.H.; Zhang, J.; Li, M.; Xie, Y.; Li, J.R.; Zhou, H.C. Highly stable Zr(IV)-based metal-organic frameworks for the detection and removal of antibiotics and organic explosives in water. J. Am. Chem. Soc. 2016, 138, 6204-6216. [CrossRef] [PubMed]

6. Gao, J.; Lu, Y.; Zhang, X.; Chen, J.; Xu, S.; Li, X.; Li, X.; Tan, F. Elucidating the electrostatic interaction of sulfonic acid functionalized SBA-15 for ciprofloxain adsorption. Appl. Surf. Sci. 2015, 349, 224-229. [CrossRef]

7. Yan, B.; Niu, C.H.; Wang, J. Kinetics, electron-donor-acceptor interactions, and site energy distribution analyses of norfloxacin adsorption on pretreated barley straw. Chem. Eng. J. 2017, 330, 1211-1221. [CrossRef]

8. Peng, X.; Hu, F.; Zhang, T.; Qiu, F.; Dai, H. Amine-functionalized magnetic bamboo-based activated carbon adsorptive removal of ciprofloxacin and norfloxacin: A batch and fixed-bed column study. Bioresour. Technol. 2018, 249, 924-934. [CrossRef] [PubMed]

9. Jabbari, V.; Veleta, J.M.; Zarei-Chaleshtori, M.; Gardea-Torresdey, J.; Villagrán, D. Green synthesis of magnetic MOF@GO and MOF@CNT hybrid nanocomposites with high adsorption capacity towards organic pollutants. Chem. Eng. J. 2016, 304, 774-783. [CrossRef]

10. Seo, P.W.; Khan, N.A.; Jhung, S.H. Removal of nitroimidazole antibiotics from water by adsorption over metal-organic frameworks modified with urea or melamine. Chem. Eng. J. 2017, 315, 92-100. [CrossRef]

11. Lu, H.; Wang, J.; Li, F.; Huang, X.; Tian, B.; Hao, H. Highly efficient and reusable montmorillonite $/ \mathrm{Fe}_{3} \mathrm{O}_{4} /$ humic acid nanocomposites for simultaneous removal of $\mathrm{Cr}(\mathrm{VI})$ and aniline. Nanomaterials 2018, 8, 537. [CrossRef] [PubMed]

12. Wang, Z.Y.; Yu, X.D.; Pan, B.; Xing, B.S. Norfloxacin sorption and its thermodynamics on surface-modified carbon nanotubes. Environ. Sci. Technol. 2010, 44, 978-984. [CrossRef] [PubMed]

13. Turco, A.; Monteduro, A.G.; Mazzotta, E.; Maruccio, G.; Malitesta, C. An innovative porous nanocomposite material for the removal of phenolic compounds from aqueous solutions. Nanomaterials 2018, 8, 350. [CrossRef] [PubMed]

14. Mo, Z.W.; Zhou, H.L.; Zhou, D.D.; Lin, R.B.; Liao, P.Q.; He, C.T.; Zhang, W.X.; Chen, X.M.; Zhang, J.P. Mesoporous metal-organic frameworks with exceptionally high working capacities for adsorption heat transformation. Adv. Mater. 2018, 30, 1704350. [CrossRef] [PubMed]

15. Oveisi, M.; Asli, M.A.; Mahmoodi, N.M. MIL-Ti metal-organic frameworks (MOFs) nanomaterials as superior adsorbents: Synthesis and ultrasound-aided dye adsorption from multicomponent wastewater systems. J. Hazard. Mater. 2018, 347, 123-140. [CrossRef] [PubMed]

16. Zheng, F.; Yang, Y.; Chen, Q. High lithium anodic performance of highly nitrogen-doped porous carbon prepared from a metal-organic framework. Nat. Comm. 2014, 5, 5261. [CrossRef] [PubMed]

17. Guan, B.Y.; Yu, L.; Lou, X.W. A dual-metal-organic-frameworks derived electrocatalyst for oxygen reduction. Energy Environ. Sci. 2016, 9, 3092-3096. [CrossRef]

18. Liu, B.; Shioyama, H.; Akita, T.; Xu, Q. Metal-organic framework as a template for porous carbon synthesis. J. Am. Chem. Soc. 2008, 130, 5390-5391. [CrossRef] [PubMed]

19. Yang, S.J.; Kim, T.; Im, J.H.; Kim, Y.S.; Lee, K.; Jung, H.; Park, C.R. MOF-derived hierarchically porous carbon with exceptional porosity and hydrogen storage capacity. Chem. Mater. 2012, 24, 464-470. [CrossRef]

20. Li, S.; Zhang, X.; Huang, Y. Zeolitic imidazolate framework-8 derived nanoporous carbon as an effective and recyclable adsorbent for removal of ciprofloxacin antibiotics from water. J. Hazard. Mater. 2017, 321, 711-719. [CrossRef] [PubMed]

21. Didaskalou, C.; Buyuktiryaki, S.; Kecili, R.; Fonte, C.P.; Szekely, G. Valorisation of agricultural waste with an adsorption/nanofiltration hybrid process: from materials to sustainable process design. Green Chem. 2017, 19, 3116-3125. [CrossRef]

22. Razali, M.; Kim, J.F.; Attfield, M.; Budd, P.M.; Drioli, E.; Lee, Y.M.; Szekely, G. Sustainable wastewater treatment and recycling in membrane manufacturing. Green Chem. 2015, 17, 5196-5205. [CrossRef]

23. Likon, M.; Cernec, F.; Svegl, F.; Saarela, J.; Zimmie, T.F. Papermill industrial waste as a sustainable source for high efficiency absorbent production. Waste Manage. 2011, 31, 1350-1356. [CrossRef] [PubMed] 
24. Liu, Y.; Gao, Z.; Wu, R.; Wang, Z.; Chen, X.; Chan, T.D. Magnetic porous carbon derived from a bimetallic metal-organic framework for magnetic solid-phase extraction of organochlorine pesticides from drinking and environmental water samples. J. Chromatogr. A 2017, 1479, 55-61. [CrossRef] [PubMed]

25. Jin, L.; Zhao, X.; Qian, X.; Dong, M. Nickel nanoparticles encapsulated in porous carbon and carbon nanotube hybrids from bimetallic metal-organic-frameworks for highly efficient adsorption of dyes. J. Colloid Interface Sci. 2018, 509, 245-253. [CrossRef] [PubMed]

26. Yuan, Y.; Yang, D.; Mei, G.; Hong, X.; Wu, J.; Zheng, J.; Pang, J.; Yan, Z. Preparation of konjac glucomannan-based zeolitic imidazolate framework-8 composite aerogels with high adsorptive capacity of ciprofloxacin from water. Colloid. Surface. A 2018, 544, 187-195. [CrossRef]

27. Niu, H.; Wang, Y.; Zhang, X.; Meng, Z.; Cai, Y. Easy synthesis of surface-tunable carbon-encapsulated magnetic nanoparticles: adsorbents for selective isolation and preconcentration of organic pollutants. ACS Appl. Mater. Inter. 2012, 4, 286-295. [CrossRef] [PubMed]

28. Fodi, T.; Didaskalou, C.; Kupai, J.; Balogh, G.T.; Huszthy, P.; Szekely, G. Nanofiltration-enabled in Situ solvent and reagent recycle for sustainable continuous-flow synthesis. ChemSusChem 2017, 10, 3435-3444. [CrossRef] [PubMed]

29. Schaepertoens, M.; Didaskalou, C.; Kim, J.F.; Livingston, A.G.; Szekely, G. Solvent recycle with imperfect membranes: A semi-continuous workaround for diafiltration. J. Memb. Sci. 2016, 514, 646-658. [CrossRef]

30. Li, N.; Yang, S.; Chen, J.; Gao, J.; He, H.; Sun, C. Electro-adsorption of tetracycline from aqueous solution by carbonized pomelo peel and composite with aniline. Appl. Surf. Sci. 2016, 386, 460-466. [CrossRef]

31. Chen, Y.Z.; Wang, C.; Wu, Z.Y.; Xiong, Y.; Xu, Q.; Yu, S.H.; Jiang, H.L. From bimetallic metal-organic framework to porous carbon: high surface area and multicomponent active dopants for excellent electrocatalysis. Adv. Mater. 2015, 27, 5010-5016. [CrossRef] [PubMed]

32. Torad, N.L.; Hu, M.; Ishihara, S.; Sukegawa, H.; Belik, A.A.; Imura, M.; Ariga, K.; Sakka, Y.; Yamauchi, Y. Direct synthesis of MOF-derived nanoporous carbon with magnetic Co nanoparticles toward efficient water treatment. Small 2014, 10, 2096-2107.

33. Ling, L.L.; Liu, W.J.; Zhang, S.; Jiang, H. Magnesium Oxide Embedded nitrogen self-doped biochar composites: fast and high-efficiency adsorption of heavy metals in an aqueous solution. Environ. Sci. Technol. 2017, 51, 10081-10089. [CrossRef] [PubMed]

34. Zhao, S.S.; Yan, T.T.; Wang, H.; Chen, G.R.; Huang, L.; Zhang, J.P.; Shi, L.Y.; Zhang, D.S. High capacity and high rate capability of nitrogen-doped porous hollow carbon spheres for capacitive deionization. Appl. Surf. Sci. 2016, 369, 460-469. [CrossRef]

35. Xie, Y.; Yang, W.; Wang, M.; Ge, X. Fibrous N-doped hierarchical porous carbon microspheres: Synthesis and adsorption performance. Chem. Eng. J. 2017, 323, 224-232. [CrossRef]

36. Wang, H.; Shi, L.; Yan, T.; Zhang, J.; Zhong, Q.; Zhang, D. Design of graphene-coated hollow mesoporous carbon spheres as high performance electrodes for capacitive deionization. J. Mater. Chem. A 2014, 2, 4739-4750. [CrossRef]

37. Sun, L.; Tian, C.; Li, M.; Meng, X.; Wang, L.; Wang, R.; Yin, J.; Fu, H. From coconut shell to porous graphene-like nanosheets for high-power supercapacitors. J. Mater. Chem. A 2013, 1, 6462-6470. [CrossRef]

38. Peng, H.; Ma, G.; Sun, K.; Mu, J.; Zhang, Z.; Lei, Z. Formation of carbon nanosheets via simultaneous activation and catalytic carbonization of macroporous anion-exchange resin for supercapacitors application. ACS Appl. Mater. Interfaces 2014, 6, 20795-20803. [CrossRef] [PubMed]

39. Wang, H.; Zhang, D.S.; Yan, T.T.; Wen, X.R.; Zhang, J.P.; Shi, L.Y.; Zhong, Q.D. Three-dimensional macroporous graphene architectures as high performance electrodes for capacitive deionization. J. Mater. Chem. A 2013, 1, 11778-11789. [CrossRef]

40. Peng, B.; Chen, L.; Que, C.; Yang, K.; Deng, F.; Deng, X.; Shi, G.; Xu, G.; Wu, M. Adsorption of antibiotics on graphene and biochar in aqueous solutions induced by $\pi-\pi$ interactions. Sci. Rep. 2016, 6, 31920. [CrossRef] [PubMed]

41. Peiris, C.; Gunatilake, S.R.; Mlsna, T.E.; Mohan, D.; Vithanage, M. Biochar based removal of antibiotic sulfonamides and tetracyclines in aquatic environments: A critical review. Bioresour. Technol. 2017, 246, 150-159. [CrossRef] [PubMed]

42. Ji, L.; Chen, W.; Duan, L.; Zhu, D. Mechanisms for strong adsorption of tetracycline to carbon nanotubes: A comparative study using activated carbon and graphite as adsorbents. Environ. Sci. Technol. 2009, 43, 2322-2327. [CrossRef] [PubMed] 
43. Zhu, H.; Chen, T.; Liu, J.; Li, D. Adsorption of tetracycline antibiotics from an aqueous solution onto graphene oxide/calcium alginate composite fibers. RSC Adv. 2018, 8, 2616-2621. [CrossRef]

44. Liang, C.; Zhang, X.; Feng, P.; Chai, H.; Huang, Y. ZIF-67 derived hollow cobalt sulfide as superior adsorbent for effective adsorption removal of ciprofloxacin antibiotics. Chem. Eng. J. 2018, 344, 95-104. [CrossRef]

45. Han, X.; Wang, H.; Zhang, L. Efficient removal of methyl blue using nanoporous carbon from the waste biomass. Water Air Soil Poll. 2018, 229, 26. [CrossRef]

2018 by the authors. Licensee MDPI, Basel, Switzerland. This article is an open access article distributed under the terms and conditions of the Creative Commons Attribution (CC BY) license (http://creativecommons.org/licenses/by/4.0/). 